\title{
Research on Comprehensive Competitive Evaluation of P2P Network Lending Platforms Based on BP Neural Network Model
}

\author{
Qizhong Deng*, Ting Liu \\ Hunan University of Science and Technology, Hunan 411201, China
}

Corresponding Author Email: 1180016@hnust.edu.cn

https://doi.org/10.18280/rces.070103

Received: 13 December 2019

Accepted: 27 February 2020

\section{Keywords:}

$B P$ neural network, factor analysis, $P 2 P$ network lending platforms

\begin{abstract}
Based on many key factors affecting the comprehensive competitiveness of $\mathrm{P} 2 \mathrm{P}$ online lending platform that include transaction time, registered capital, popularity points, dispersion points and transparency points, this paper constructs evaluation index system of P2P network lending platform. The 12 secondary indicators of the evaluation system were processed through factor analysis, and BP neural network model was used to quantitatively evaluate comprehensive competitiveness of $\mathrm{P} 2 \mathrm{P}$ online lending platforms. The results show that in the selected P2P network lending platform, the highest score of comprehensive competitiveness evaluation is only 0.62 which indicates that the overall competitiveness of China's P2P industry platforms is not strong. The non-equilibrium development pattern of P2P network lending platform seems to be obvious, at least there were regional differences and background differences. Most of the top platforms for comprehensive competitiveness evaluation scores are located in China's first-tier cities or have a background of listed and state-owned capital.
\end{abstract}

\section{INTRODUCTION}

In the development process of China's asset securitization, with the birth of YU Ebao and rapid growth of its asset scale, the Internet financial market has exploded to a large extent. As one of the main types of Internet finance, P2P network lending has been favored by many investors with its low investment threshold, high profitability and strong liquidity. Since the establishment of Paipaidai (NYSE: PPDF), China's first P2P network lending platform in 2007, the P2P industry has grown at an amazing rate in China. According to the statistics of China's first and authoritative P2P online loan investment and wealth management industry portal WDZJ.com, as of February, 2019, the number of P2P network lending platforms in China has reached 6,619, and the volume of P2P industry in the month was recorded 95.652 billion yuan. The net loan comprehensive rate of return was $9.937 \%$. At the same time, there have been many problems with the emergence of unhealthy phenomena such as running away (manager disappears) and cash withdrawals, from 471 in February, 2015 to 2,706 in February, 2019. The number of problematic platforms added in 4 years has been reached 2,235. It shows that many platforms cannot achieve healthy development of operational efficiency in a highly competitive environment. How to take effective measures to improve the competitiveness of the online lending platform and improve the efficiency of the P2P industry and guide the steady development of China's P2P network lending platform will be an important issue that Chinese $\mathrm{P} 2 \mathrm{P}$ regulators need to solve.

After the establishment of the world's first P2P company, Zopa, in the UK in 2005, the P2P industry has sprung up in China and other countries, and this field has gradually attracted scholars' attention in China and other countries. Outside China Scholarly focus was on the following aspects:
(1) The behavioral characteristics of borrowing and lending in the platform. For example, Shen et al. [1] and Lee et al. [2] found that "herding behavior" is common among investors in the P2P network lending market, while Herzenstein et al. [3] have documented that the herding effect is a rational expression of fund borrowers. The more obvious the borrowing behavior of the herding, the higher the probability of that the lender will get repayment on time. but Kim [4] found that he rationality of investors' herding behaviour is not deterministic but changes with the investors' credit assessment style in each market. (2) In terms of the factors affecting the success rate of borrowing and the interest rate of borrowing. Freedman and Jin [5] have pointed out that the financial information provided by the borrower on the platform is the main influencing factor affecting the success rate of the loan. However, Ravina [6] and Duarte et al. [7] have believed that the factors affecting the borrower's borrowing success rate and borrowing rate are not only financial information, but also the demographic characteristics of the borrower's age, gender, appearance, ethnicity and so on. At the same time, Dorfleitner et al. [8] and Nowak et al. [9] pointed out that soft information such as loan descriptions written by the borrower will also affect it. In addition, Emekter et al. [10] use the data of P2P lending platform to evaluate platform borrower credit risk, and Serrano-Cinca et al. [11] think the profit scoring system is better than the credit scoring system. The Chinese P2P industry have started later than some developed countries and Chinese scholars' research focus on P2P online lending industry is different from that of other countries, mainly focusing on the risk and supervision of the P2P online lending platforms and the relationship between platform and bank. For example, Li et al. [12] believe that the Chinese P2P network lending platform should establish a third-party fund custody mechanism to avoid the "Ponzi scheme" recurring. Meanwhile, 
Liu and Shen [13] and Zhang [14] have proposed to improve China's credit system with credit information and rating as the main content to eliminate information asymmetry in credit risk. In response to the relationship between the P2P online lending platform and the bank, Tang [15] pointed out that the P2P network lending platform is both a substitute and a supplement for banks. Zhang et al. [16] found that P2P lending balance and average P2P lending rate have a positive impact on the average domestic bank lending balance, and it will have a negative impact by the contrary. In addition, a few scholars have conducted empirical analysis on the operation of the P2P platform. For example, Mao [17] and Tan et al. [18] have conducted empirical research on the effectiveness and herding effect of the P2P market.

By reviewing the existing literature, it can be found that the existing research has mainly focus on the operation of the $\mathrm{P} 2 \mathrm{P}$ network lending platform, the behavior of platform participants and the risk of the platform. However, the empirical analysis of the comprehensive competitiveness of the P2P network lending platform is still relatively small, but the comprehensive competitiveness is not only a direct reflection of the overall strength level of the P2P network lending platform, but also an important regulatory basis for the relevant regulatory authorities. Therefore, this paper uses factor analysis and BP neural network model to evaluate the comprehensive competitiveness of the selected 60 P2P network lending platforms. Moreover, it deeply analyzes the differentiated characteristics of the comprehensive competitiveness of the platform in China's P2P industry platform in different regions and in different contexts.

\section{CONSTRUCTION OF THE EVALUATION INDEX SYSTEM}

In the light of commercial banks and enterprises' comprehensive competitiveness studies, we have constructed an evaluation system for the comprehensive competitiveness of China's P2P network lending platform [19-21]. Based on the principles established by the indicators, combined with field research and expert feedback, we finally determined that the main factors affecting the comprehensive competitiveness of the P2P network lending platform are profitability, operational capability, market strength, risk control capability and development potential as five primary indicators. After statistical analysis, 12 secondary indicators such as transaction points, technical points, popularity points, liquidity points, leverage points, dispersive points and brand points were selected to represent the comprehensive competitiveness of China's P2P network lending platform. The evaluation system and the specific indicators are as shown in Table 1:

Table 1. P2P network lending platform comprehensive competitiveness evaluation index system

\begin{tabular}{|c|c|c|c|}
\hline $\begin{array}{l}\text { Primary } \\
\text { indicators }\end{array}$ & \multicolumn{2}{|c|}{ Secondary indicators } & Meaning of the indicators \\
\hline Profitability & $\begin{array}{l}\text { Transaction } \\
\text { points }\end{array}$ & $\mathrm{X}_{1}$ & $\begin{array}{l}\text { According to the weighted trading volume and time-weighted trading volume of the past three } \\
\text { months, the higher the transaction score, the higher the trading volume of the platform, and the } \\
\text { stronger its profitability. }\end{array}$ \\
\hline \multirow{2}{*}{$\begin{array}{l}\text { Operational } \\
\text { capability }\end{array}$} & $\begin{array}{l}\text { Technical } \\
\text { points }\end{array}$ & $\mathrm{X}_{2}$ & $\begin{array}{l}\text { According to the platform system independent research and development, website per capita } \\
\text { response time, website security vulnerability detection, APP update frequency, WeChat client, } \\
\text { data transmission security, account security, IT team strength, etc., it is a direct reflection of the } \\
\text { platform's technical strength, the higher the technical points indicate that the platform is more } \\
\text { technically strong. }\end{array}$ \\
\hline & $\begin{array}{l}\text { Popularity } \\
\text { points }\end{array}$ & $\mathrm{X}_{3}$ & $\begin{array}{l}\text { The indicator is derived by weighting the number of investors and borrowers in the last three } \\
\text { months, reflecting the number of borrowers and investors on the platform. Generally, the higher } \\
\text { the popularity score, the more the platform is welcomed by investors and borrowers, and the } \\
\text { operating conditions are also healthier. }\end{array}$ \\
\hline \multirow{3}{*}{$\begin{array}{l}\text { Market } \\
\text { strength }\end{array}$} & $\begin{array}{l}\text { Registered } \\
\text { capital }\end{array}$ & $\mathrm{X}_{4}$ & $\begin{array}{l}\text { Refers to the amount that the online loan platform registers with the company registration } \\
\text { authority according to law. The higher the registered capital of the platform, the higher the } \\
\text { formality of the platform, indicating the platform has a stronger ability to ensure the investor's } \\
\text { funds security. }\end{array}$ \\
\hline & Age & $\mathrm{X}_{5}$ & $\begin{array}{c}\text { Refers to the total number of months from the establishment of the online loan platform to } \\
\text { September 2018. The longer platform operation history shows that the platform experience is } \\
\text { more abundant and the market strength is stronger. }\end{array}$ \\
\hline & $\begin{array}{l}\text { Number of } \\
\text { employees }\end{array}$ & $\mathrm{X}_{6}$ & $\begin{array}{c}\text { The greater the number of platform employees, the greater the scale of the platform, that is, the } \\
\text { platform is stronger. }\end{array}$ \\
\hline \multirow{3}{*}{$\begin{array}{l}\text { Risk control } \\
\text { capability }\end{array}$} & $\begin{array}{l}\text { Liquidity } \\
\text { points }\end{array}$ & $\mathrm{X}_{7}$ & $\begin{array}{l}\text { Based on the consideration of the liquidity of investors and P2P platforms, the index of the } \\
\text { project and the net outflow of funds are adjusted to obtain the indicator. The higher the points, the } \\
\text { lower the risk of platform redemption. }\end{array}$ \\
\hline & $\begin{array}{l}\text { Leverage } \\
\text { points }\end{array}$ & $\mathrm{X}_{8}$ & $\begin{array}{l}\text { Calculated based on geographical leverage, over } 10 \text { times leverage, TOP } 10 \% \text { overdue capital } \\
\text { ratio, and leverage to be received. The higher the points, the stronger the risk tolerance of the } \\
\text { platform. }\end{array}$ \\
\hline & $\begin{array}{l}\text { Dispersive } \\
\text { points }\end{array}$ & $\mathrm{X}_{9}$ & $\begin{array}{l}\text { This indicator is used to characterize the dispersion of platform borrowing and investment funds, } \\
\text { and is also an indirect representation of P2P platform risk control capabilities. The greater the } \\
\text { points, the less operational risk the platform has. }\end{array}$ \\
\hline \multirow{2}{*}{$\begin{array}{l}\text { Development } \\
\text { potential }\end{array}$} & Brand points & $\mathrm{X}_{10}$ & $\begin{array}{l}\text { It is a direct reflection of the platform's reputation through integrating fund recognition, } \\
\text { headquarters city, Alexa ranking, shareholder and team background and event impact. The higher } \\
\text { the brand score, the higher the platform's reputation, indicating that it is more recognized by } \\
\text { investors. }\end{array}$ \\
\hline & $\begin{array}{l}\text { Transparency } \\
\text { points }\end{array}$ & $\mathrm{X}_{11}$ & $\begin{array}{l}\text { According to the degree of publication of the company's basic information, operational data } \\
\text { information, and loan information, it indicates the transparency of the information of the } \\
\text { platform. }\end{array}$ \\
\hline
\end{tabular}




\section{P2P ONLINE LENDING PLATFORM COMPREHENSIVE COMPETITIVENESS EVALUATION METHOD AND STEPS}

\subsection{Evaluation method selection}

1. Factor Analysis: In the comprehensive competitiveness evaluation of $\mathrm{P} 2 \mathrm{P}$ online lending platform, researchers usually hope to collect more and more comprehensive indicators to have a more comprehensive and complete understanding of the problem. However, the multivariate indicator system will increase the workload of collecting data to a certain extent. Moreover, in many cases, there will be correlations between many variables that may have different performances of the same attribute of the P2P network lending platform. The main idea of factor analysis is to reduce dimensionality and simplify data. By analyzing the intrinsic dependencies in the data of many indicators, the correlation and overlap between the indicators are excluded, and the original multidimensional variable indicators are reorganized to find the common factors. $[22,23]$ The common factor is used to represent the main information of the original indicator system. Mathematical model is:

$$
\left\{\begin{array}{l}
X_{1}=\alpha_{11} F_{1}+\alpha_{12} F_{2}+\ldots+\alpha_{1 m} F_{m}+\alpha_{1} \varepsilon_{1} \\
X_{2}=\alpha_{21} F_{2}+\alpha_{22} F_{2}+\ldots+\alpha_{2 m} F_{m}+\alpha_{2} \varepsilon_{2} \\
\ldots \\
X_{p}=\alpha_{p 1} F_{1}+\alpha_{P 2} F_{2}+\ldots+\alpha_{p m} F_{m}+\alpha_{p} \varepsilon_{p}
\end{array}\right.
$$

$F_{1}, F_{2}, \cdots, F_{m}$ is a common factor, $\varepsilon_{i}$ is a special factor, contains random errors, and only works for $X_{i}$, where $\alpha_{i j}$ is factor loading.

2. BP (Back-Propagation BPNNs) neural network: As an adaptive nonlinear learning system, neural network processes information by simulating human brain biological nervous system, and it is also a multi-layer feed-forward network that propagates backward according to error. It learns in the state of known input and ideal output, and then continuously adjusts the weight and threshold of the network according to the back propagation of the error between the expected output and the actual output, thereby, it continuously reduces the expected output and actual output of the neural network. The sum of the squares of the errors makes the actual network output value as close as possible to the expected value, thus, improving the adaptability of network learning. A typical BP neural network typically includes an input layer, a hidden layer, and an output layer and it includes at least one hidden layer [24]. The specific learning algorithm is as follows:

(1) The BP neural network is initialized and the connection weights of each layer are assigned to a random number in the interval $(-1,1)$, that is, the weight of the input layer to the hidden layer is $w_{i j}$, and the weight of the hidden layer to the output layer is $w_{j k}$. Connection thresholds are $a$ and $b$ respectively. Set the error function $e$, given the calculation accuracy value $\varepsilon$ and the maximum number of learning $M$.
(2) Calculate the output of the hidden layer. According to the input vector $X_{1}, X_{2}, \cdots, X_{n}$, the corresponding expected output vector $Y_{l}, Y_{2}, \cdots, Y_{m}$ and the weight $w_{i j}$, threshold of the input layer to the hidden layer $a$, the output $H_{j}$ of the hidden layer is:

$$
H_{j}=g\left(\sum_{i=1}^{n} w_{i j} x_{i}+\alpha_{j}\right)
$$

In the formula, $j=1,2, \cdots, l, l$ is the number of hidden layer nodes, and $g$ represent the implicit layer excitation function.

(3) Calculate the output of the output layer

$$
O_{k}=\sum_{j=1}^{l} H_{j} w_{j k}+b_{k}
$$

(4) Error calculation. The error formula is set to:

$$
E=\frac{1}{2} \sum_{k=1}^{m}\left(Y_{k}-O_{k}\right)^{2}
$$

In the formula, $Y_{k}$ is the expected output, and we set $Y_{k^{-}}$ $O_{k}=e_{k}$, that is:

$$
E=\frac{1}{2} \sum_{k=1}^{m} e_{k}^{2}
$$

And $i=1,2, \cdots, n ; j=1,2, \cdots, l ; k=1,2, \cdots, m$.

(5) Update weights. The formula for updating the weight is:

$$
\begin{aligned}
& w_{i j}=w_{i j}+\eta H_{j}\left(1-H_{j}\right) x_{i} \sum_{k=1}^{m} w_{j k} e_{k} \\
& w_{j k}=w_{j k}+\eta H_{j} e_{k}
\end{aligned}
$$

In the formula, $i=1,2, \cdots, n ; j=1,2, \cdots, l ; k=1,2, \cdots, m ; \eta$ is Learning rate.

(6) Update Threshold. Based on error function $e_{k}$, the updated connection thresholds are:

$$
\begin{aligned}
& a_{j}=a_{j}+\eta H_{j}\left(1-H_{j}\right) \\
& b_{k}=b_{k}+e_{k}
\end{aligned}
$$

And $j=1,2, \cdots, l ; k=1,2, \cdots, m$.

(7) The next input mode is selected for repeated training until the neural network output error reaches the target error, and the training is completed.

\subsection{BP neural network model evaluation procedures}

At present, BP neural network model has been widely and successfully applied in the fields of demand forecasting, competitiveness evaluation and company performance evaluation. Based on the factor analysis method, this paper 
uses BP neural network model to evaluate the comprehensive competitiveness of P2P network lending platform. The main steps are as follows: Firstly, factor analysis is used to simplify the dimension reduction process, and common factors are used to replace the original indicators, and they are used as input variables of BP neural network; secondly, the input data is standardized; finally, the constructed BP neural network model is used to evaluate the comprehensive competitiveness of the selected P2P network lending platform.

\section{EMPIRICAL ANALYSIS}

\subsection{Data source and processing}

Due to the large number of P2P network lending platforms in China and the different operating status of each platform, the information disclosure of some platforms is not perfect enough to study and analyze the comprehensive competitiveness of each platform. Therefore, we selected the platform of the top 60 rankings from WDZJ.com in September 2018 for comprehensive competitiveness evaluation. The 60 P2P network lending platforms are well represented in the industry and the data is easy to collect. The index values of the platform are all official website from WDZJ.com and various platforms. Since the different indicator units are inconsistent, direct incorporating in the neural network may cause errors. Therefore, the original data is normalized before further analysis and all the data is mapped into interval $[0,1]$. The calculation formula is as follows:

$$
x_{i}=\frac{x-\min (x)}{\max (x)-\min (x)}
$$

\subsection{Factor analysis}

Using SPSS20.0 to perform KMO sampling suitability test and Bartlett spherical test on the indicator data, the results show that the KMO statistic is 0.681, while the Bartlett spherical test has a square value of 479.043 and a $P$ value of 0.000 . $\mathrm{T}$ Therefore, rejecting the correlation coefficient matrix as the original hypothesis of the unit matrix, indicating that there is a correlation between the variables. It means that the original indicator system is suitable for factor analysis. In addition, according to the criterion with the eigenvalue greater than 1 , and the varimax rotation method to extract the factor. The top 5 factors with eigenvalues greater than 1 are $F_{1}, F_{2}, F_{3}$, $F_{4}$ and $F_{5}$, contributing rates are $37.099 \%, 15.089 \%, 12.575 \%$, $9.931 \%$, and $8.455 \%$, respectively. The cumulative contribution rate is $83.149 \%$, and the missing information is less, indicating that the extracted common factors have strong explanatory power for the indicators. Finally according to formula (8)

$$
\begin{aligned}
& F=0.4462 * F_{1}+0.1815 * F_{2}+0.1512 * F_{3} \\
& +0.1194 * F_{4}+0.1017 * F_{5}
\end{aligned}
$$

Calculate the comprehensive scores of each platform, as shown in Table 2.

Table 2. Comprehensive scores and rankings of sample P2P network lending platforms

\begin{tabular}{cccccc}
\hline Platform & Expected & Ranking & Platform & Expected & Ranking \\
\hline Lujinfu & 0.625453 & 1 & Jinkaidai & 0.170256 & 56 \\
Yirendai & 0.518920 & 5 & Shanyidai & 0.235418 & 50 \\
Renrendai & 0.538080 & 4 & Daokoudai & 0.371402 & 31 \\
Paipaidai, & 0.602569 & 3 & Shoujinwang & 0.315631 & 42 \\
Weidaiwang & 0.615641 & 2 & Shitoujinron & 0.219868 & 53 \\
Madaicaifu & 0.510131 & 8 & E-rongsuo & 0.346023 & 35 \\
Xiaoyingwangjin & 0.484650 & 12 & Koudailicai & 0.379548 & 29 \\
Tuandaiwang & 0.497157 & 10 & Guangzhou-e-dai & 0.231350 & 51 \\
Jimuhezi & 0.475186 & 14 & Pengjinsuo & 0.161674 & 58 \\
Yilongdai & 0.474403 & 15 & Shou-E-jia & 0.280942 & 44 \\
Fenghuangjinron & 0.498716 & 9 & Jiashiliu & 0.238355 & 48 \\
Dianrong & 0.448028 & 18 & Laocaibao & 0.423649 & 22 \\
Tounawang & 0.425800 & 21 & Honglinchuangtou & 0.372240 & 30 \\
Aiqianjin & 0.511255 & 7 & Wanglibao & 0.354606 & 33 \\
Youliwang & 0.516898 & 6 & Haiyirong & 0.188972 & 55 \\
5lrenpin & 0.474356 & 16 & Renrenjucai & 0.385641 & 28 \\
PPmoney & 0.480632 & 13 & Lianlianjinrong & 0.267636 & 46 \\
Wangxinpuhui & 0.492557 & 11 & Guangxindai & 0.398403 & 26 \\
Niwodai & 0.470252 & 17 & E-dushiqianbao & 0.280147 & 45 \\
Yangqianguan & 0.438273 & 19 & Dongfanghui & 0.213659 & 54 \\
Hexindai & 0.421004 & 23 & Hezhong-e-dai & 0.342960 & 36 \\
Kaixindai & 0.163719 & 57 & Qilerong & 0.238300 & 49 \\
Mindaitianxia & 0.352045 & 34 & Tuodaojinfu & 0.338125 & 38 \\
Souyidai & 0.323230 & 40 & Lianzidai & 0.329506 & 39 \\
Jintouhang & 0.322536 & 41 & Huiyanjinrong & 0.288578 & 43 \\
Xiangshangjinfu & 0.386290 & 27 & e-lutongxin & 0.220443 & 52 \\
Bugunonchang & 0.363269 & 32 & Mizhuang & 0.398521 & 25 \\
91wangcai & 0.416102 & 24 & Huanghejinrong & 0.247206 & 47 \\
Bojindai & 0.340213 & 37 & Guangjinjinfu & 0.141959 & 60 \\
Youjinfu & 0.437082 & 20 & Zhubaodai & 0.157567 & 59 \\
\hline & & & & &
\end{tabular}




\subsection{BP neural network evaluation}

Based on the factor analysis results, the scores of $F_{1}, F_{2}, F_{3}$, $F_{4}$ and $F_{5}$ are taken as input sample and the number of input layer nodes is set to 5 . At the same time, the comprehensive score processed by the factor analysis of each platform is the expected output value, and the number of output layer nodes is set to 1 . The hidden layer does not currently have an ideal analytical formula to determine its reasonable number of neuron nodes, which is mainly determined according to the empirical formula $l=\sqrt{a+b}+\varepsilon$, where $a$ is the number of input layer nodes, $b$ is the number of output layer nodes, and $\varepsilon$ belongs to any constant of $[0,10]$. Through many experiments, we have found that the most suitable number of hidden layer nodes is 7 .

Building the BP neural network model not only requires data processing on the input layer nodes, output layer nodes, and hidden layer nodes, but also sets parameters such as the training function, learning function and training target of the network. After many experiments, the learning function and the training function are determined as the LEARNGDM function and the TRAINLM function respectively; the excitation function of the output layer and the hidden layer is set to the PURELIN function and the TAN-SIGMOD function; the performance function is the MSE function; the training times are set 1000; the error precision is $1 \times 10^{(-10)}$; other parameters such as learning rate directly adopt the default value.

The data of 51 platform have randomly been selected from the 60 collected platforms that were used as training sample and 9 platforms were used as test sample. The nntool function in MATLAB2016b is used for neural network learning. According to factor analysis, scores of the common factors $F_{1}$, $F_{2}, F_{3}, F_{4}$, and $F_{5}$ of the platform are taken as input values, and the comprehensive score $\mathrm{F}$ is taken as the expected value. After BP neural network training, the expected target was achieved when the number of training reached 771 times and the actual output value of the neural network and the expected output value were linearly regressed. The similarity between the two was found to have $\mathrm{R}=0.99375$. The higher the similarity, the more consistent the two values are, indicating that the actual output of the neural network has a good fit to the expected output. The trained neural network will be tested on 9 randomly selected platforms. The test results are shown in Table 3.

It can be seen from Table 3 that the actual output value of the BP neural network is basically consistent with the expected output value. The minimum absolute error between the two is 0.0000023 , the maximum absolute error is 0.000402 , and the error percentage is only $0.0186 \%$. The trained BP neural network was used to evaluate the comprehensive competitiveness of the selected $60 \mathrm{P} 2 \mathrm{P}$ platforms. The results are shown in Table 4.

According to Table 4 results, the comprehensive competitiveness score of China's P2P network lending platform is uneven. There are only three companies with scores above 0.6, namely Lujinfu, Paipaidai and Weidaiwang, and the number only accounts for the total number of selected platforms that is $5 \%$. They are first echelon with better overall competitiveness. The five platforms with scores between 0.5 and 0.6 were Yirendai, Renrendai, Madaicaifu, Aiqianjin and Youliwang, accounting for $8.33 \%$. There are two platforms with scores below 0.2, which are Guangjinjinfu and Zhubaodai. Their comprehensive competitiveness is poor in the selected 60 platforms. As a subsidiary of Ping An Group, Lujinfu has strong background strength. At the same time, Ping An Bank, Ping An Pratt \& Whitney and Ping An Insurance also provide support for its business development. So, it has stronger competitiveness than other platforms. Its evaluation score is the highest 0.625442 . In addition, among the 60 selected platforms, eight of the top ten platforms with comprehensive competitiveness scores are located in first-tier cities in China. Only two platforms, namely, group loan network and microloan network, are located in non-first-tier cities, respectively in Dongguan and Hangzhou as the first-tier cities have a high degree of marketization, there will be developed economy and fierce competition. Therefore, the platform will strive to improve its management level and service quality, and thus, promote the comprehensive competitiveness of the platform. In addition, seven of the top ten platforms in the ranking belong to listed companies or state-owned enterprises. This is mainly because listed companies and state-owned enterprise platforms have stronger financial strength than others platforms, and they have a relatively complete risk control system and technical level. It will be more successful when working with banks and third-party organizations, so, the comprehensive competitiveness score for this category of platforms is relatively high. By comparing and analyzing Tables 2 and 4, we can also find that the BP neural network model output results are almost consistent with the comprehensive score results obtained by the factor analysis method. Explain that the combination of factor analysis and BP neural network not only simplifies structure of BP neural network model, but also eliminates the influence of subjective factors and also improves the learning efficiency of neural network, thus, ensuring the accuracy of comprehensive competitiveness evaluation.

Table 3. Output error comparison table of sample P2P network lending platforms tested

\begin{tabular}{ccccc}
\hline Platform & Expected & Actual output & Absolute error & Error percentage \\
\hline Aiqianjin & 0.511255 & 0.511272 & 0.0000167 & 0.0000327 \\
PPmoney & 0.480632 & 0.480624 & 0.0000082 & 0.0000170 \\
91wangcai & 0.416102 & 0.416088 & 0.0000133 & 0.0000319 \\
Shoujindai & 0.315631 & 0.315629 & 0.0000023 & 0.0000073 \\
Guangzhou-e-dai & 0.23135 & 0.231331 & 0.0000191 & 0.0000825 \\
Jiashiliu & 0.238355 & 0.238315 & 0.0000402 & 0.0001684 \\
e-lutongxin & 0.220443 & 0.220421 & 0.0000215 & 0.0000975 \\
Huanghejinrong & 0.247206 & 0.247193 & 0.0000130 & 0.0000526 \\
Guangjinjinfu & 0.141959 & 0.141986 & 0.0000263 & 0.0001860 \\
\hline
\end{tabular}


Table 4. Comprehensive competitiveness evaluation results and ranking of sample P2P network lending platforms

\begin{tabular}{|c|c|c|c|c|c|c|c|c|c|}
\hline Platform & Background & Location & Score & Ranking & Platform & Background & Location & Score & Ranking \\
\hline Lujinfu & Listed & Shanghai & 0.625442 & 1 & Jinkaidai & State-owned & Xian & 0.170208 & 56 \\
\hline Yirendai & Listed & Beijing & 0.518934 & 5 & Shanyidai & Listed & Shenzhen & 0.235411 & 50 \\
\hline Renrendai & $\begin{array}{l}\text { Venture capital } \\
\text { department }\end{array}$ & Beijing & 0.538106 & 4 & Daokoudai & State-owned & Beijing & 0.371399 & 31 \\
\hline Paipaidai, & Listed & Shanghai & 0.602604 & 3 & Shoujindai & State-owned & Beijing & 0.315629 & 42 \\
\hline Weidaiwang & Listed & Hangzhou & 0.615641 & 2 & Shitoujinron & Private & Shanghai & 0.219857 & 53 \\
\hline Madaicaifu & State-owned & Shanghai & 0.510141 & 8 & E-rongsuo & Listed & Shenzhen & 0.346022 & 35 \\
\hline Xiaoyingwangjin & Listed & Shenzhen & 0.484644 & 12 & Koudailicai & Private & Shanghai & 0.379547 & 29 \\
\hline Tuandaiwang & $\begin{array}{c}\text { Venture capital } \\
\text { department }\end{array}$ & Dongguan & 0.497158 & 10 & Guangzhou-e-dai & Listed & Guangzhou & 0.231331 & 51 \\
\hline Jimuhezi & $\begin{array}{l}\text { Venture capital } \\
\text { department }\end{array}$ & Beijing & 0.475172 & 14 & Pengjinsuo & Listed & Shenzhen & 0.161673 & 58 \\
\hline Yilongdai & Listed & Beijing & 0.474399 & 15 & Shou-E-jia & State-owned & Beijing & 0.280942 & 44 \\
\hline Fenghuangjinron & Listed & Beijing & 0.498723 & 9 & Jiashiliu & Listed & Hangzhou & 0.238315 & 48 \\
\hline Dianrong & $\begin{array}{c}\text { Venture capital } \\
\text { department }\end{array}$ & Shanghai & 0.448006 & 18 & Laocaibao & Private & Shanghai & 0.423649 & 22 \\
\hline Tounawang & Listed & Shenzhen & 0.425790 & 21 & Honglinchuangtou & Private & Shenzhen & 0.372239 & 30 \\
\hline Aiqianjin & $\begin{array}{c}\text { Venture capital } \\
\text { department }\end{array}$ & Beijing & 0.511272 & 7 & Wanglibao & Listed & Beijing & 0.354615 & 33 \\
\hline Youliwang & $\begin{array}{c}\text { Venture capital } \\
\text { department }\end{array}$ & Beijing & 0.516909 & 6 & Haiyirong & $\begin{array}{c}\text { Venture capital } \\
\text { department }\end{array}$ & Beijing & 0.188976 & 55 \\
\hline 51renpin & Listed & Hangzhou & 0.474357 & 16 & Renrenjucai & Private & Shenzhen & 0.385643 & 28 \\
\hline PPmoney & $\begin{array}{c}\text { Venture capital } \\
\text { department }\end{array}$ & Guangzhou & 0.480624 & 13 & Lianlianjinrong & Private & Beijing & 0.267625 & 46 \\
\hline Wangxinpuhui & Listed & Beijing & 0.492553 & 11 & Guangxindai & Private & Beijing & 0.398404 & 26 \\
\hline Niwodai & Private & Shanghai & 0.470241 & 17 & E-dushiqianbao & Private & Hangzhou & 0.280144 & 45 \\
\hline Yangqianguan & Private & Beijing & 0.438259 & 19 & Dongfanghui & State-owned & Shanghai & 0.213640 & 54 \\
\hline Hexindai & Listed & Beijing & 0.42099 & 23 & Hezhong-e-dai & Listed & Shenzhen & 0.342961 & 36 \\
\hline Kaixindai & Banking & Nanjing & 0.163722 & 57 & Qilerong & Listed & Hefei & 0.238266 & 49 \\
\hline Mindaitianxia & State-owned & Guangzhou & 0.352051 & 34 & Tuodaojinfu & $\begin{array}{c}\text { Venture capital } \\
\text { department }\end{array}$ & Hangzhou & 0.338136 & 38 \\
\hline Souyidai & Listed & Beijing & 0.323253 & 40 & Lianzidai & $\begin{array}{c}\text { Venture capital } \\
\text { department }\end{array}$ & Hangzhou & 0.329506 & 39 \\
\hline Jintouhang & State-owned & Hangzhou & 0.32254 & 41 & Huiyanjinrong & State-owned & Hefei & 0.288568 & 43 \\
\hline Xiangshangjinfu & Private & Beijing & 0.386289 & 27 & e-lutongxin & State-owned & Shenzhen & 0.220421 & 52 \\
\hline Bugunonchang & Listed & Shenzhen & 0.363266 & 32 & Mizhuang & Listed & Hangzhou & 0.398522 & 25 \\
\hline 91wangcai & $\begin{array}{c}\text { Venture capital } \\
\text { department }\end{array}$ & Beijing & 0.416088 & 24 & Huanghejinrong & Listed & Hangzhou & 0.247193 & 47 \\
\hline Bojindai & State-owned & Nanchang & 0.340225 & 37 & Guangjinjinfu & State-owned & Guangzhou & 0.141986 & 60 \\
\hline Youjinfu & Listed & Shenzhen & 0.437074 & 20 & Zhubaodai & Listed & Shenzhen & 0.157576 & 59 \\
\hline
\end{tabular}

\section{CONCLUSION AND SUGGESTION}

Based on the BP neural network model, this paper evaluates the comprehensive competitiveness of the selected $60 \mathrm{P} 2 \mathrm{P}$ network lending platforms. The following conclusions are drawn from the paper. First, the comprehensive competitiveness of China's $\mathrm{P} 2 \mathrm{P}$ network lending platforms is large and the overall competitiveness of the platform is weak. The Lujinfu platform with the highest evaluation score is only 0.6 and it is still 0.48 higher than the last place, Guangjinjinfu platform. The gap in the score of comprehensive competitiveness evaluation is obvious. Second, platform background and regional differences are important factors affecting the comprehensive competitiveness of China's P2P network lending platform. The P2P network lending platform located in first-tier cities and with listed companies or stateowned enterprises have a higher ranking of comprehensive competitiveness evaluation scores. In the light of results, this article has the following policy implications:

First of all, establish a differentiated regulatory mechanism. P2P online lending is an important mode of Internet finance. As the number of its platforms continues to expand, the development of the industry is increasingly concerned by the regulatory authorities. Further, it is difficult for the regulatory authorities to achieve full regulatory coverage with limited resources. The department should conduct differentiated supervision according to the comprehensive competitiveness of the P2P online lending platform. For platforms with stronger comprehensive competitiveness, we should focus on ensuring that they can maintain a high degree of competitive development, and thus, maximize the efficiency of industry supervision. And then, strengthen cooperation and communication between platforms. A sound credit system will greatly help the P2P network lending platform to avoid risks beforehand. The platform will consume a lot of cost in collecting information on the borrower's credit rating process. Therefore, if the platform strengthens communication, and efforts should be made to build a credit inquiry system covering the entire $\mathrm{P} 2 \mathrm{P}$ industry. This will not only reduce the cost of the platform, but also reduce the risk of default. Finally, accelerate product innovation in P2P network lending platform. In the context of increasingly fierce competition in the digital financial market, the provision of customized and differentiated products and services for borrowers is increasingly becoming a key element of the platform's foothold in the fast-growing industry. Innovative products and services can promote the comprehensive competitiveness of the platform itself.

\section{REFERENCES}

[1] Shen, D., Krumme, C., Lippman, A. (2010). Follow the profit or the herd? exploring social effects in Peer-to-Peer 
lending. IEEE Second International Conference on Social Computing, pp. 137-144. https://doi.org/10.1109/SocialCom.2010.28

[2] Lee, E., Lee, B. (2012). Herding behavior in online P2P lending: an empirical investigation. Electronic Commerce Research and Applications, 11(5): 495-503. https://doi.org/10.1016/j.elerap.2012.02.001

[3] Herzenstein, M., Dholakia, U.M., Andrews, R.L. (2011). Strategic herding behavior in Peer-to-Peer loan auctions Journal of Interactive Marketing, 25(1): 27-36. https://doi.org/10.1016/j.intmar.2010.07.001

[4] Kim, D. (2019). The importance of detailed patterns of herding behaviour in a P2P lending market. Applied Economics Letters.

[5] Freedman, S., Jin, G.Z. (2008). Do social networks solve information problems for Peer-to-Peer lending? evidence from Prosper. Com. Net Institute Working Paper, pp. 843. https://doi.org/10.2139/ssrn.1304138

[6] Ravina, E. (2008). Love \& Loans: The effect of beauty and personal characteristics in credit markets. SSRN Electronic Journal,

$1-79$. https://doi.org/10.2139/ssrn.1107307

[7] Duarte, J., Siegel, S., Young, L. (2012). Trust and credit: the role of appearance in Peer-to-Peer lending. Review of Financial Studies, 25(8): 2455-2483. https://doi.org/10.1093/rfs/hhs071

[8] Dorfleitner, G., Priberny, C., Schuster, S., Stoiber, J., Weber, M., de Castro, I., Kammler, J. (2016). Description-text related soft information in Peer-to-Peer lending - evidence from two leading European platforms. Journal of Banking \& Finance, 64: 169-187. https://doi.org/10.1016/j.jbankfin.2015.11.009

[9] Nowak, A., Ross, A., Yencha, C. (2018). Small business borrowing and Peer-to-Peer lending: Evidence from lending club. Contemporary Economic Policy, 36(2): 318-336. https://doi.org/ 10.1111/coep.12252

[10] Emekter, R., Tu, Y.B., Jirasakuldech, B., Lu, M. (2015). Evaluating credit risk and loan performance in online Peer-to-Peer (P2P) lending. Applied Economics, 47(1): 54-70. https://doi.org/10.1080/00036846.2014.962222

[11] Serrano-Cinca, C., Gutierrez-Nieto, B. (2016). The use of profit scoring as an alternative to credit scoring systems in peer-to-peer (P2P) lending. Decision Support Systems, 89: 113-122 https://doi.org/10.1016/j.dss.2016.06.014

[12] Li, Y.X., Chen, F., Jin, Y.F. (2014). A study on the regulation of the internet finance. Journal of Zhejiang University (Humanities and Social Sciences), 44(4): 8797. https://doi.org/10.3785/j.issn.1008942X.2014.02.121

[13] Liu, H., Shen, Q.J. (2015). International experience and enlightenment for China on Peer-to-Peer network lending supervision. Journal of Hebei University of
Economics and Business, 36(2): 56-61. https://doi.org/10.14178/j.cnki.issn10072101.2015.02.013

[14] Zhang, A.J. (2019). The risk and prevention of P2P network lending platform in China. Finance Economy, 502(04): 147-148. https://doi.org/10.14057/j.cnki.cn431156/f.2019.04.065

[15] Tang, H. (2019). Peer-to-Peer lenders versus banks: bubstitutes or complements? Review of Financial Studies, 32(5): 1900-1938. https://doi.org/10.1093/rfs/hhy 137

[16] Zhang, Z., Hu, W.J., Chang, T.Y. (2019). Nonlinear effects of P2P lending on bank loans in a panel smooth transition regression model. International Review of Economics \& Finance, 59: 468-473. https://doi.org/10.1016/j.iref.2018.10.010

[17] Mao, L. (2017). Empirical research of herd behavior based on P2P lending. Statistics \& Decision, 8: 169-172. https://doi.org/10.13546/j.cnki.tjyjc.2017.08.043

[18] Tan, C., Sun, B.Z., Wang, J.N. (2014). Research on the herd behavior in P2P network lending platform: An empirical analysis based on logistic model. South China Finance, 12: 30-37. https://doi.org/10.3969/j.issn.10079041.2014.12.006

[19] Cabrita, M.D. M.F., da Silva, M.D.R., Rodrigues, A.M.G., Duenas, M.D.M. (2017). Competitiveness and disclosure of intellectual capital: an empirical research in Portuguese banks. Journal of Intellectual Capital, 18(3): 486-505. https://doi.org/10.1108/JIC-11-2016-0112

[20] Chi, G.T., Wang, J.K., Du, J. (2006). Competitiveness appraisal model based on gray system theory. Control and Decision, 3: 347-351. https://doi.org/10.3321/j.issn:1001-0920.2006.03.025

[21] Pan, X., Ju, X.F., Chen, J. (2013). Research on competitiveness evaluation of high-tech industry in 29 regions of China based on factor analysis. Inquiry Into Economic Issues, 4: 65-69. https://doi.org/10.3969/j.issn.1006-2912.2013.04.012

[22] Flach, L., Castro, J.K., de Mattos, L.K. (2017). Financial performance evaluation of Brazilian energy with factor analysis and decision tree. Revista Eletronica De Estrategia E Negocios-Reen, 10(1): 201-225. https://doi.org/10.19177/reen.v10e12017201-225

[23] Singh, A., Singla, B. (2019). A factor analysis approach for analyzing the service quality of banks. Jims $8 m-$ The Journal of Indian Management \& Strategy, 24(3): 60-63. https://doi.org/ 10.5958/0973-9343.2019.00026.7

[24] Momeni, E. Armaghani, D.J., Hajihassani, M., Amin, M.F.M. (2015). Prediction of uniaxial compressive strength of rock samples using hybrid particle swarm optimization-based artificial neural networks. Measurement, 60: 50-63. https://doi.org/10.1016/j.measurement.2014.09.075 